\title{
The Effect of High pH and Calcium on Tobacco Leaf Protoplast Fusion
}

\author{
W. A. Keller * and G. Melchers \\ Max-Planck-Institut für Biologie, Tübingen \\ (Z. Naturforsch. 28 c, 737-741 [1973] ; received October 18, 1973) \\ Fusion, protoplasts, high $\mathrm{pH}$ and Calcium, complementation
}

\begin{abstract}
High frequencies of fusion were induced between isolated tobacco leaf protoplasts when they were incubated at $37^{\circ} \mathrm{C}$ in the presence of $0.05 \mathrm{M} \mathrm{CaCl}_{2}$ in $0.4 \mathrm{M}$ mannitol at $\mathrm{pH} 10.5$. Subsequent to the fusion treatment the protoplasts were washed and cultured in a suitable medium and within two weeks, actively dividing cell colonies were observed. The fusion treatment had no irreversible, deleterious effects on the protoplasts.
\end{abstract}

The induced fusion of isolated plant protoplasts with the aim of producing interspecific somatic hybrid plants has drawn the attention of many plant scientists ${ }^{1-5}$. Induced protoplast fusion refers to the achievement of fusion between protoplasts that are free in suspension and it differs from spontaneous fusion which may occur as a result of plasmodesmatal expansion during isolation and which cannot be utilized for somatic hybridization ${ }^{6,7}$, Carlson et al. ${ }^{8}$ have recently reported the formation of a vegetative, somatic or, as they call it, parasexual hybrid ("burdo", Winkler ${ }^{9,10}$ ) resulting from the induced fusion of protoplasts from two Nicotiana species.

Several methods have been reported to induce protoplast fusion. These include manipulation with a perfusion micropipette ${ }^{11}$, treatment with $\mathrm{NaNO}_{3}{ }^{12,14,8}$, artificial seawater ${ }^{15,16}$ lysozyme ${ }^{17}$ and deplasmolyzing osmotic shock ${ }^{7}$. With existing methods it has been difficult to induce high frequencies of fusion and retain the viability of vacuolate protoplasts such as leaf protoplasts ${ }^{18,13,17}, 8$. In the present paper we wish to report evidence for the stimulation of high frequencies of protoplast fusion by calcium ions at high $\mathrm{pH}$ conditions without irreparable damage to the protoplasts.

\section{Material and Methods}

\section{Source of protoplasts}

The upper expanding leaves of three Nicotiana tabacum varieties were utilized for protoplast iso-

\footnotetext{
* Present address: Ottawa Research Station, Department of Agriculture, Ottawa, Ontario, Canada.

Requests for reprints should be sent to Max-Planck-Institut für Bioolgie, Abteilung Melchers, D-7400 Tübingen, Corrensstr. 4l.
}

lation. The varieties were N.tabacum var. "Samsun" with 48 chromosomes growing in greenhouse conditions and two "haploid" chlorophyll deficient, light sensitive varieties of $N$.tabacum designated as $\mathrm{sl}_{1} \mathrm{sl}_{2}$ (from now on called "s", sublethal) and vi-A $A_{1}$ (called "v", virescent). The "haploid" forms with 24 chromosomes of the light sensitive varieties were produced by anther culture techniques ${ }^{19,20}$ and were grown in climate chambers at $700-800 \mathrm{~lx}$ (continuous) at $28{ }^{\circ} \mathrm{C}$ and $75 \%$ relative humidity. Under these conditions the plants show light green leaves. They are multiplied by cuttings. The $F_{1}$ hybrids produced by crossing $\mathrm{v} \times \mathrm{s}$ with 48 chromosomes complement for a normal dark green chlorophyll character and they grow vigorously in high light intensities present in the greenhouse or produced artificially.

\section{Protoplast isolation}

The leaves were surface sterilized by a two-min immersion in a $0.3 \%$ commercial detergent solution followed by a fourmin immersion in $10 \mathrm{vol} / \%$ of a commercial desinfection solution, $\mathrm{NaClO}$, containing $150 \mathrm{~g} / \mathrm{l}$ active $\mathrm{Cl}$. After a triple washing in distilled water the midribs were removed and the leaves were cut into narrow ( $2 \mathrm{~mm}$ or less) strips with a razor blade. The leaf strips were placed in $100 \mathrm{ml}$ Erlenmeyer flasks containing $0.7 \mathrm{M}$ mannitol and were then shaken at 120 strokes $/ \mathrm{min}(5 \mathrm{~cm}$ stroke) at $25{ }^{\circ} \mathrm{C}$ for $30 \mathrm{~min}$. The mannitol solution was replaced by a $0.7 \mathrm{M}$ mannitol solution containing 0.5\% (w/v) Macerozyme $4 \mathrm{~S}$ (All Japan Biochemicals Co., Nishinomiya, Japan) and 0.5\% $(\mathrm{w} / \mathrm{v})$ potassium dextran sulfate (Meioto Sangyo Co., Meitosangyo, Nagoya, Japan) adjusted to $\mathrm{pH}$ 5.7. The Macerozyme solution was drawn into the intercellular spaces by a vacuum infiltration period of one min.

The leaf pieces were then agitated at 120 strokes/ mit at $25^{\circ} \mathrm{C}$ for $15 \mathrm{~min}$. The supernatant of the first maceration treatment was discarded but the 
cells harvested from four successive 20-min macerations were collected for cellulase treatment. The cells were pelleted by centrifugation at $50 \times \mathrm{g}$ for $3 \mathrm{~min}$ and then suspended in a cellulase solution consisting of $2 \%(\mathrm{w} / \mathrm{v})$ Onozuka cellulase $4 \mathrm{~S}$ (All Japan Biochemicals Co.) and $0.1 \%(\mathrm{w} / \mathrm{v})$ potassium dextran sulfate in $0.7 \mathrm{~m}$ mannitol at $\mathrm{pH} 5.5$. The cells remained in the cellulase for $2.5-3$ hours (without shaking 2 hours $=24{ }^{\circ} \mathrm{C}, 1 / 2$ hour $=$ $37^{\circ} \mathrm{C}$, if necessary) during which they were converted to protoplasts.

The protoplasts suspension was filtered through a $100 \mu$ pore mesh, the protoplasts were pelleted $(3 \mathrm{~min}$ at $50 \times \mathrm{g})$ and then resuspended in $0.8 \mathrm{M}$ mannitol.

\section{Protoplast fusion}

The protoplasts in $0.8 \mathrm{M}$ mannitol were pelleted and then resuspended in the fusion inducing solution which was buffered at $\mathrm{pH} 10.5(0.05 \mathrm{M}$ glycine$\mathrm{NaOH})$ and which contained $0.05 \mathrm{M} \mathrm{CaCl}_{2} \cdot 2 \mathrm{H}_{2} \mathrm{O}$ and $0.4 \mathrm{M}$ mannitol. The protoplasts were again pelleted $(\max g=50,3 \mathrm{~min})$ and the centrifuge tubes were placed into a $37^{\circ} \mathrm{C}$ water bath. Samples were removed at various time intervals and light microscopic observations were made to determine the degree of aggregation and the rate of fusion.

\section{Protoplast culture}

When the number of protoplasts undergoing fusion was considered to be maximal the tubes were removed from the water bath and the fusioninducing solution was replaced by post fusion wash $\left(0.6 \mathrm{~m}\right.$ mannit., $\left.0.05 \mathrm{M} \mathrm{CaCl}_{2} \cdot 2 \mathrm{H}_{2} \mathrm{O}\right)$. After standing $30 \mathrm{~min}$ the protoplasts were washed twice with the culture medium of Nagata and Takebe ${ }^{21}$ and were then plated in agar as described by Takebe et al. ${ }^{22}$ or cultured as $50 \mu \mathrm{l}$ droplets as described by Kao et al. ${ }^{23}$ in plastic petri dishes sealed with parafilm. The dishes were maintained in the dark or in dim light $(300 \mathrm{~lx})$ for a period of $24-48$ hours and were then moved to continuous light $(3000 \mathrm{~lx})$ at $28{ }^{\circ} \mathrm{C}$ and $70 \%$ relative humidity ${ }^{24}$.

\section{Results}

\section{Protoplast fusion}

The protoplasts isolated by the sequential method described above were generally quite uniform and underwent very low frequencies ( $1 \%$ or less) of spontaneous fusion (Fig. $\left.1^{*}\right)$. The initial isolation

* Figs 1 and 2 see Table on page 740 a. of single cells by Macerozyme treatment caused the breakage of interconnecting plasmodesmatal strands which would have allowed spontaneous fusion to occur.

Observations subsequent to the fusion treatment revealed that protoplasts began to aggregate after $10-15 \mathrm{~min}$ of incubation. The degree of aggregation, as judged by the number of aggregates as well as the number of protoplasts within aggregates increased with time and after $25-30 \mathrm{~min}$, fusion of protoplasts within the aggregates was observed. The fusion events involved from two or a few protoplasts (Fig. 2) up to large numbers undergoing multiple fusions (Fig. $3 *$ ). After $60 \mathrm{~min}$ of incubation many of the protoplasts, and especially the larger fusion bodies, became unstable and burst. In subsequent studies the fusion solution was removed after $40-45 \mathrm{~min}$ in order that the protoplasts could be cultured. The frequency of fusion was difficult to determine because of the multiple fusions and tightly aggregated clusters but in most instances $20-50 \%$ of the protoplasts were involved in a fusion event. A good preparation of viable protoplasts free of undigested or broken cells was necessary for fusion. Generally, large amounts of debris indicated a poor protoplast preparation in which the plasma membranes were apparently in a weakened condition unsuitable to undergo fusion. Washing the protoplasts with $0.8 \mathrm{M}$ mannitol helped to remove debris and made conditions more conducive for fusion.

\section{Factors affecting protoplast fusion}

The calcium concentration was observed to be an important factor in fusion (Table I). If the calcium level was less than $0.03 \mathrm{M}$ there was very little aggregation and fusion. At a $0.1 \mathrm{M} \mathrm{CaCl}_{2}$ concentration a very high degree of aggregation was observed but the fusion frequency was not greater than, and usually lower than at $0.05 \mathrm{M} \mathrm{CaCl}_{2}$. If the osmotic stabilizer was replaced with $0.2 \mathrm{M} \mathrm{CaCl}_{2}$ a very extensive aggregation of protoplasts into large, easily visible clusters occurred but the fusion frequency remained quite low. If calcium was lacking from the system the protoplasts became loosely associated into long thread-like forms but the fusion frequency remained very low and it was not increased by subsequent addition of calcium.

* Fig. 3 see Table on page 740 b. 
Table I. The effects of calcium concentration on aggregation and fusion of tobacco leaf protoplasts. The total osmolarity of the solutions (including the buffer and mannitol) was approximately $0.60 \mathrm{M}$. The $\mathrm{pH}$ level was 10.5 . A represents aggregation and $\mathrm{F}$ represents fusion. Degree of aggregation or fusion is represented by,,$++++++a$, whereas absence of effect is represented by - .

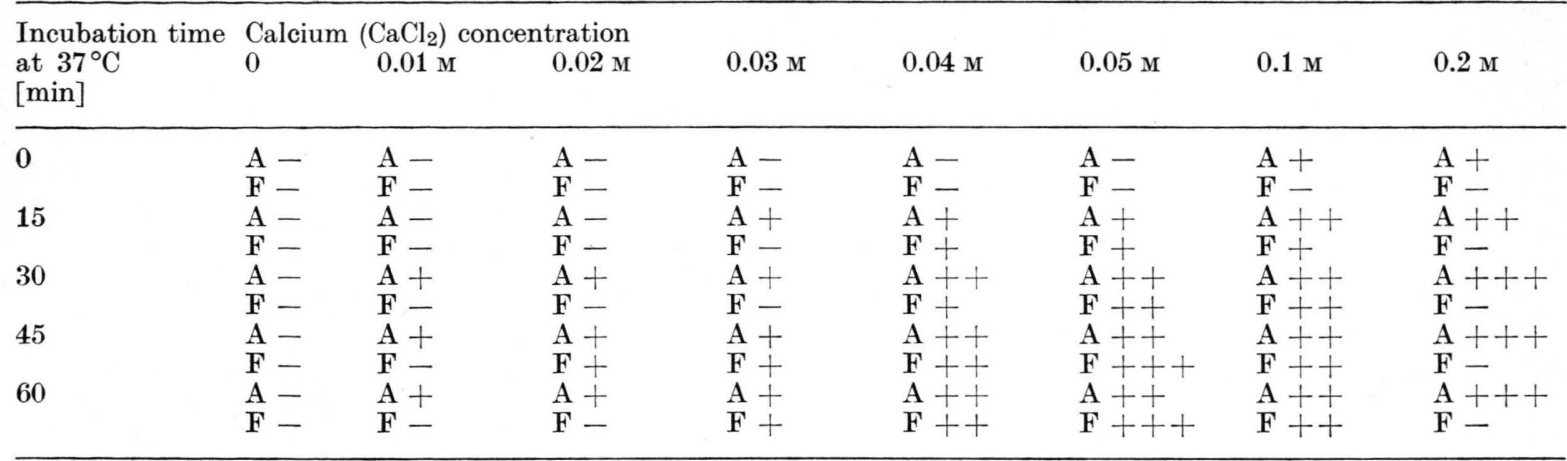

$a+$ Involving $5-10 \%$ of the protoplasts; ++ involving $10-25 \%$ of the protoplasts; +++ involving more than $25 \%$ of the protoplasts.

Chloride ions did not appear to be inhibitory to the fusion process since identical observations were made in the presence of $\mathrm{Ca}\left(\mathrm{NO}_{3}\right)_{2}$. Magnesium could not be substituted for calcium since it failed to induce either protoplast aggregation or fusion.

The $\mathrm{pH}$ of the fusion medium was not extremely critical (Table II). In the $\mathrm{pH}$ range of 8.5-9.0 there was a lower degree of aggregation and fusion than in the optimal range of $\mathrm{pH} 9.5-10.5$. Levels of $\mathrm{pH}$ higher than 11.0 tended to cause protoplast damage after $30 \mathrm{~min}$, although protoplasts from haploid $\mathrm{v}$ that had been treated at $\mathrm{pH} 11.0$ for 30 min survived the treatment, divided in culture and produced colonies which later differentiated into shoots in the medium B3s of Sacristán and Melchers ${ }^{25}$. The type and concentration of the osmotic stabilizer also played a significant role in the fusion system. If the mannitol concentration was raised from $0.4 \mathrm{M}$ to $0.7 \mathrm{M}$ both aggregation and fusion were retarded, but if the mannitol concentration was lowered to $0.1 \mathrm{M}$, aggregation was stimulated but the protoplasts were unstable and frequently burst. Mild hypotonic conditions were considered to be optimal for fusion. Substitution of sucrose for mannitol had no significant effect on fusion. Substitution of urea for mannitol stimulated the rate of fusion but it caused protoplast bursting within $30 \mathrm{~min}$. Substitution of mannitol by $\mathrm{KCl}, \mathrm{NaNO}_{3}$, or $\mathrm{Mg}\left(\mathrm{NO}_{3}\right)_{2}$ resulted in very extensive aggregation but did not favor fusion.

Incubation temperature dramatically affected protoplast fusion rate. Aggregation and fusion were not observed if the protoplasts were incubated at $0{ }^{\circ} \mathrm{C}$. At $23{ }^{\circ} \mathrm{C}$ the protoplasts aggregated slowly

Table II. The effect of $\mathrm{pH}$ level on aggregation and fusion of tobacco leaf protoplasts. The protoplasts were maintained in $0.05 \mathrm{M} \mathrm{CaCl}_{2}, 0.4 \mathrm{~m}$ mannitol, $0.05 \mathrm{~m}$ buffer. The terms A, F,,,++++++ , and - are the same as for Table I. D represents protoplast deterioration and death.

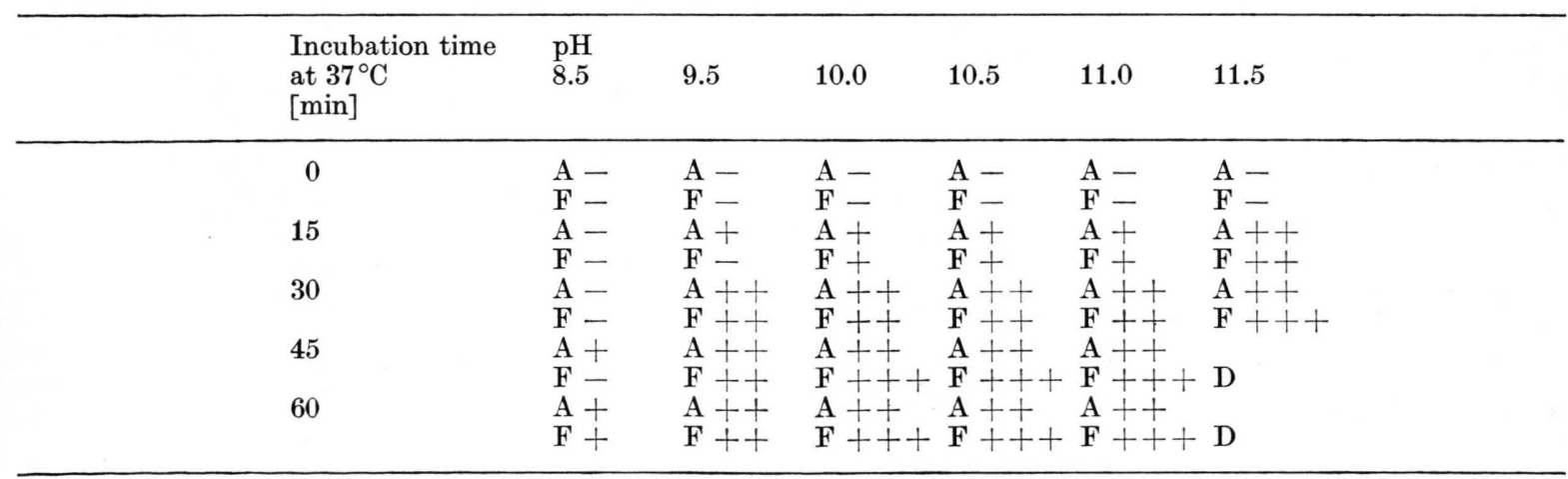


and underwent some fusion after two hours. Rapid aggregation occurred at $45^{\circ} \mathrm{C}$ and protoplasts underwent fusion within $30 \mathrm{~min}$ but deterioration and bursting occurred after $30 \mathrm{~min}$ of incubation. A temperature of $37^{\circ} \mathrm{C}$ was considered to be optimal for inducind high frequencies of fusion with a minimal effect on viability. Pelleting the protoplasts subsequent to the addition of the fusion solution had a marked effect on the degree of aggregation and fusion. Samsun protoplasts would aggregate and fuse quite readily without centrifugation but the "haploid" s and v protoplasts had to be pelleted in order to induce high frequencies of fusion.

\section{Protoplast culture}

Protoplasts subjected to the fusion treatment and subsequently cultured in the medium of Nagata and Takebe ${ }^{21}$ underwent division and developed into small colonies within two weeks. The large protoplast bodies formed by multiple fusions either failed to survive post-fusion washing or disintegrated within 48 hours in culture. We have not yet been able to determine the fate of fusion products involving two or a few protoplasts but it is certainly possible that such fusion products from two protoplasts could survive, regenerate a cell wall, undergo nuclear fusion, and ultimately undergo cell division.

\section{Discussion}

A calicum solution buffered at high $\mathrm{pH}$ induces leaf protoplast aggregation followed by high frequencies of fusion. The protoplasts have been able to tolerate the fusion treatment and could be successfully cultured. Although sodium nitrate has been reported to induce fusion between isolated protoplasts ${ }^{12}$, it has generally not been successfully used to induce high fusion frequencies between vacuolated protoplasts such as leaf protoplasts ${ }^{18,3}$. Lysozyme has been reported to induce protoplast agglutination followed by fusion but it also appeared to be toxic ${ }^{17}$. Concanavalin $\mathrm{A}^{26}$ and immunological methods ${ }^{27}$ have been used to induce protoplast agglutination but apparently there was no reported increase in fusion.

A method of fusing erythrocytes by high $\mathrm{pH}$ and calcium has been reported ${ }^{28,29}$, however, there are differences between this method and the method we have described for plant protoplast fusion. A pH level of at least 10.0 was required to induce erythrocyto fusion ${ }^{29}$, but we observed fusion at lower $\mathrm{pH}$ levels. The fusion method described by Toister and Loyter ${ }^{29}$ required the cells to be pretreated at high $\mathrm{pH}$ at $37^{\circ} \mathrm{C}$ followed by treatment with calcium ions in the cold $\left(0^{\circ}-4{ }^{\circ} \mathrm{C}\right)$ to induce agglutination which in turn was followed by a high temperature $\left(37^{\circ} \mathrm{C}\right)$ treatment, to induce fusion. We have found optimal fusion conditions by treating the protoplasts with calcium and high $\mathrm{pH}$ at $37^{\circ} \mathrm{C}$.

Temperature level during the fusion treatment was an important factor determining rate and frequency of fusion. Similar observations were made by Ahkong et al. ${ }^{30}$ when they reported a remarkable increase in the erythrocyte fusion at $37^{\circ} \mathrm{C}$.

It has been suggested that high $\mathrm{pH}$ conditions induce the formation of intramembraneous lysophospholipids such as lysolecithin and lysophosphatidylethanolamine ${ }^{29}$. Lysolecithin has been shown to induce animal cell fusion ${ }^{31}$ and it is possible that intramembraneous lysolecithin would induce fusion between plant protoplasts. Isolated plant protoplasts are known to have a surface negative charge ${ }^{32}$. High $\mathrm{pH}$ conditions may change some characters of the membrane, thereby creating conditions favorable for aggregation. Calcium may act by stabilizing the protoplasts against lysis and by linking the membranes between different protoplasts.

The observation that protoplasts can be cultured subsequent to the fusion treatment would indicate that this method is promising for somatic hybridization studies. Experiments are in progress to determine the effectiveness of this method in fusing the complementing, haploid chlorophyll-deficient tobacco varieties $\mathrm{s}$ and $\mathrm{c}$. If the selection pressure of the complemented diploid hybrid against the light sensitive haploid parents in high light intensities is good enough then this method could be generally used for fusion studies with many plants. Light sensitive chlorophyll deficient mutants are very common among higher plants.

We thank Mrs. M. Keller and Mrs. G. Labib for excellent technical assistance and Drs. L. SchildeRentschler and P. Maliga for helpful discussions. We also thank Dr. D. U. Gerstel, North Carolina State University, Raleigh, USA, for seeds of the tobacco varieties $\operatorname{sl}_{1} \mathrm{sl}_{2}$ (="s") and vi- $\mathrm{A}_{1}$ (="v"). One of the authors (W.A.K.) acknowledges the receipt of a Canada National Research Council Postdoctoral Fellowship which made this study possible. 


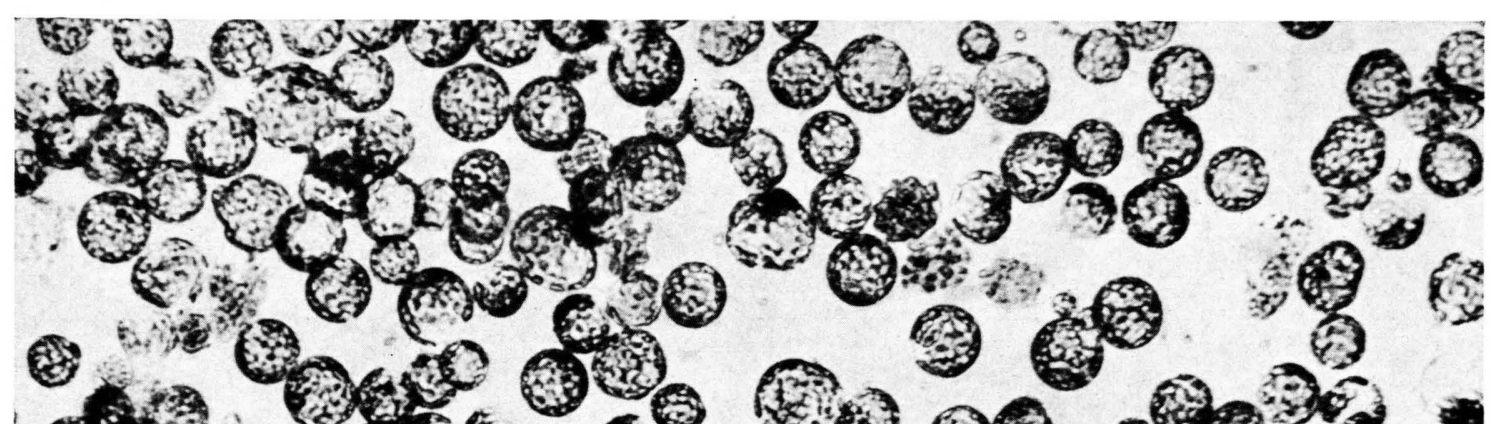

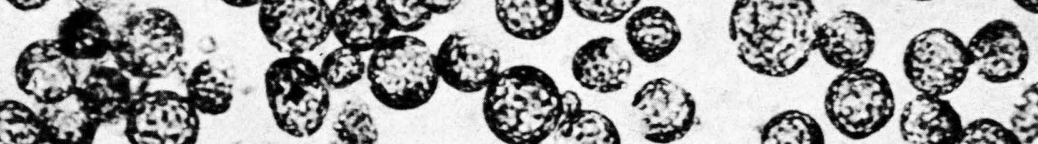

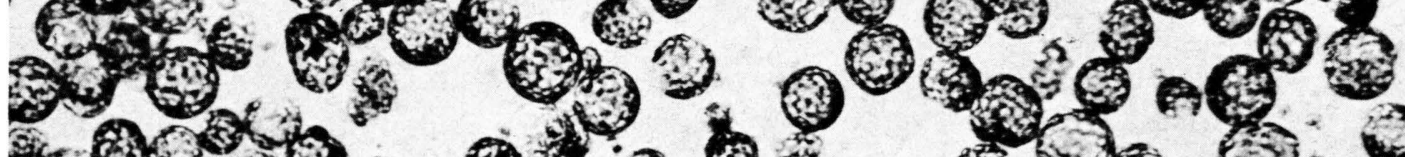

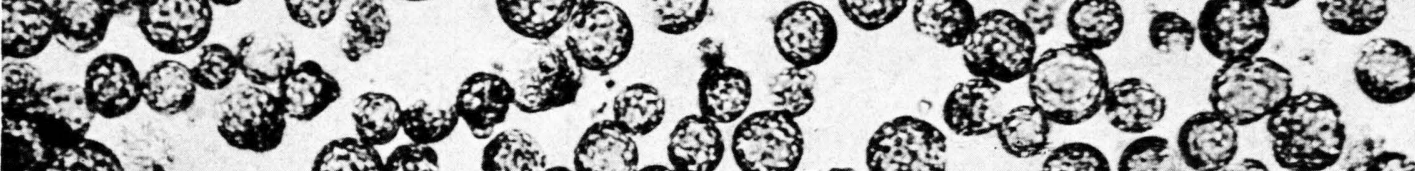
4 (5)

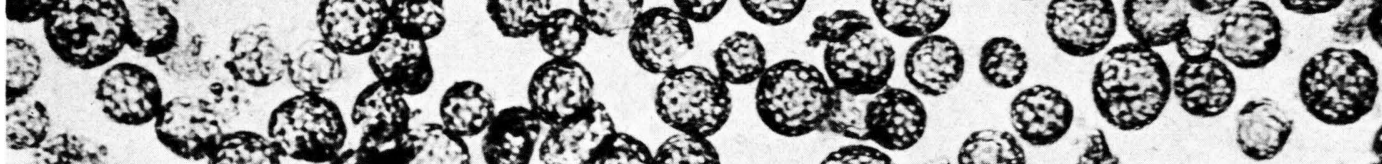

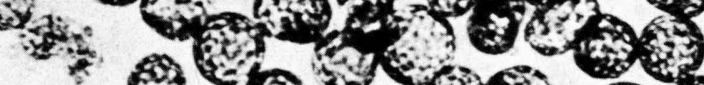

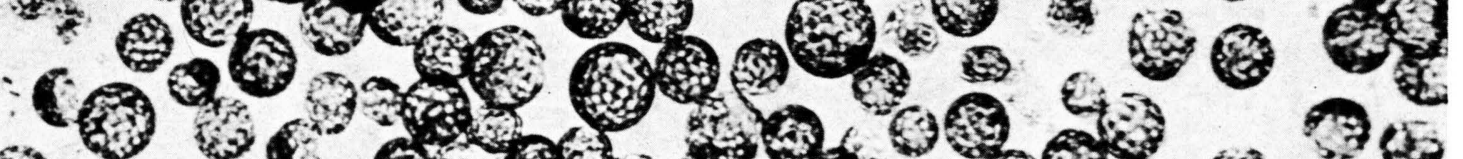

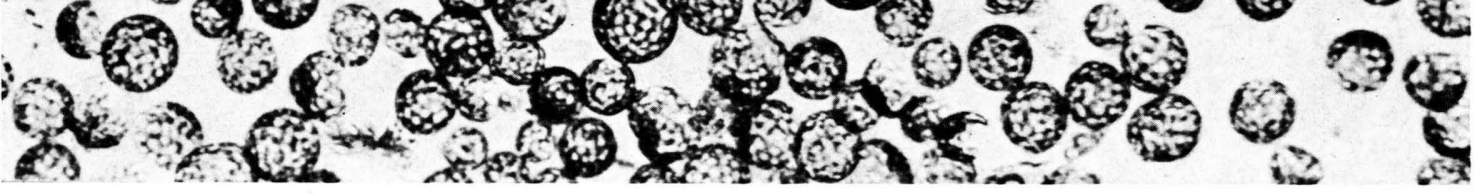

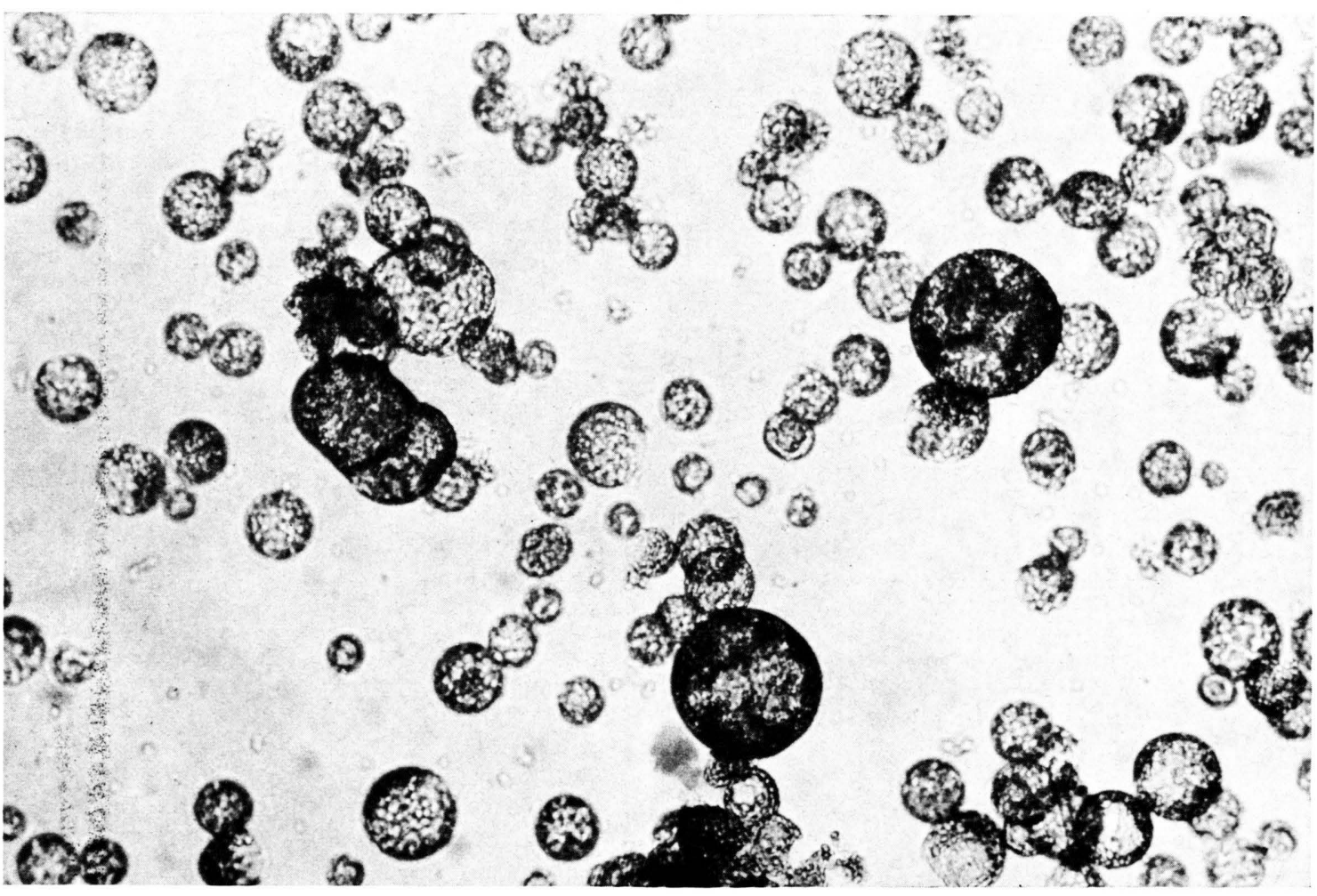

Fig. 2. Fusion events involving a few protoplasts. 


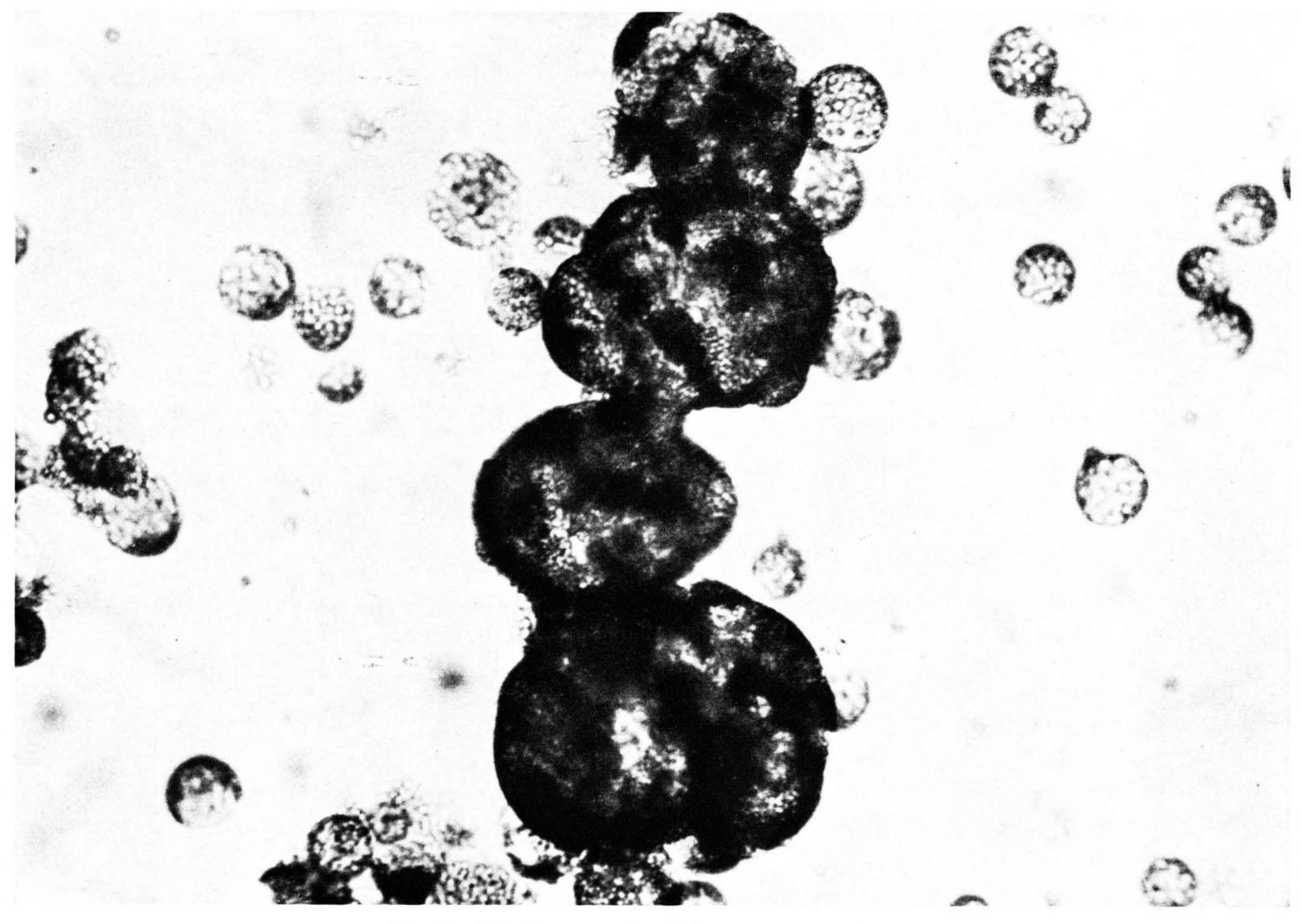

Fig. 3. A fusion event involving many protoplasts. 
1 R. U. Schenk and A. C. Hildebrandt, Amer. J. Bot. 55, 731 [1968].

2 L. G. Nickell and J. G. Torrey, Science [Washington] 166, 1068 [1969].

3 E. C. Cocking, Annu. Rev. Plant Physiol. 23, 29 [1972].

4 G. Melchers and G. Labib, Coll. Internat. CNRS No. 212, Protoplastes et fusion, p. 367, 1973.

5 P. S. Carlson, Proc. nat. Acad. Sci. USA 70, 598 [1973].

${ }^{6}$ L. A. Withers and E. C. Cocking, J. Cell Sci. 11, 59 [1972].

7 W. A. Keller, B. L. Harvey, K. N. Kao, R. A. Miller, and O. L. Gamborg, Coll. Internat. CNRS No. 212, Protoplastes et fusion, p. 455, 1973.

8 P. S. Carlson, H. H. Smith, and R. D. Dearing, Proc. nat. Acad. Sci. USA 69, 2292 [1972].

9 H. Winkler, Ber. dtsch. bot. Ges. 25, 568 [1907].

10 H. Winkler, Planta 27, 680 [1938].

11 R. U. Schenk and A. C. Hildebrandt, Coll. Internat. CNRS No. 193, Cultures de tissues, p. 319, 1970.

12 J. B. Power, S. E. Cummins, and E. C. Cocking, Nature [London] 225, 1016 [1970].

13 I. Potrykus, Nature [London], New Biol. 231, 57 [1971].

14 T. Kameya and N. Takahashi, Japan. J. Genetics 47, 215 [1972].

15 H. Binding, Z. Pflanzenphysiol. 55, 305 [1966].

16 T. Eriksson, Coll. Internat. CNRS No. 193, Cultures de tissues, p. 297, 1970.
17 I. Potrykus, III. Internat. Symp. Yeast Protoplasts, Salamanca, p. 317, 1972.

18 J. B. Power and E. C. Cocking, Sci. Progr. 59, 181 [1971].

19 S. Guha and S. C. Maheswari, Nature [London] 4957 , 497 [1966].

20 J. P. Bourgin and J. P. Nitsch, Ann. Physiol. vég. Paris 9, 377 [1967].

21 T. Nagata and I. Takebe, Planta 99, 12 [1971].

22 I. Takebe, G. Labib, and G. Melchers, Naturwissenschaften 58, 318 [1971].

${ }^{23}$ K. N. Kao, W. A. Keller, and R. A. Miller, Exp. Cell Res. 62, 338 [1970].

24 G. Enzmann-Becker, Z. Naturforsch. 28 c, 470 [1973].

${ }_{25}$ M. D. Sacristán and G. Melchers, Mol. Gen. Genetics 105, 317 [1969].

26 L. A. Withers, Coll. Internat. CNRS No. 212 Protoplastes et fusion, p. 517, 1973.

27 J. X. Hartmann, K. N. Kao, O. L. Gamborg, and R. A. Miller, Planta 112, 45 [1973].

28 Z. Toister and A. Loyter, Biochem. biophysica Acta [Amsterdam] 241, 719 [1971].

29 Z. Toister and A. Loyter, J. biol. Chemistry 248, 422 [1973].

30 Q. F. Ahkong, F. C. Cramp, D. Fisher, J. I. Howell, W. Tampion, M. Verrinder, and J. A. Lucy, Nature [London] New Biol. 242, 215 [1973].

31 J. A. Lucy, Nature [London] 227, 815 [1970].

32 A. W. Ruesink, Plant Physiol. 47, 192 [1971]. 